\title{
THE SUMMER MEETING AT ANN ARBOR
}

The forty-first summer meeting and eighteenth colloquium of the Society was held at the University of Michigan, Ann Arbor, Michigan, from Tuesday to Friday, September 10-13, 1935. The Mathematical Association of America met Monday afternoon, Tuesday morning, and Tuesday evening. About two hundred seventy-five persons attended the meetings, among whom were the following one hundred seventy-seven members of the Society:

J. R. Abernethy, C. R. Adams, R. P. Agnew, N. L. Anderson, R. C. Archibald, W. L. Ayres, G. B. Banks, G. M. Bareis, W. D. Baten, Samuel Beatty, A. A. Bennett, Felix Bernstein, H. L. Black, G. A. Bliss, Henry Blumberg, J. W. Bradshaw, J. B. Brandeberry, Richard Brauer, R. W. Brink, H. E. Buchanan, J. D. Burk, W. H. Bussey, W. D. Cairns, B. H. Camp, C. C. Camp, J. W. Campbell, W. B. Carver, R. V. Churchill, C. J. Coe, L. W. Cohen, J. T. Colpitts, Max Coral, A. T. Craig, C. C. Craig, A. R. Crathorne, M. M. Culver, H. B. Curry, D. R. Curtiss, Wayne Dancer, H. T. Davis, F. F. Decker, L. L. Dines, F. G. Dressel, Ben Dushnik, P. S. Dwyer, H. P. Evans, H. S. Everett, F. J. Feinler, Peter Field, C. H. Fischer, N. C. Fisk, W. B. Ford, J. S. Frame, T. C. Fry, Lachlan Gilchrist, D. C. Gillespie, J. W. Glover, Cornelius Gouwens, L. M. Graves, E. B. Grennan, V. G. Grove, J. G. Hardy, W. L. Hart, M. L. Hartung, O. C. Hazlett, E. R. Hedrick, H. C. Hicks, T. H. Hildebrandt, J. J. L. Hinrichsen, L. A. Hopkins, Harold Hotelling, E. M. Hull, W. A. Hurwitz, M. H. Ingraham, Dunham Jackson, R. L. Jeffery, E. H. Johnson, M. M. Johnson, B. W. Jones, C. D. Jones, H. S. Kaltenborn, L. C. Karpinski, A. J. Kempner, E. E. Knight, F. W. Kokomoor, H. W. Kuhn, E. P. Lane, R. E. Langer, C. G. Latimer, V. S. Lawrence, E. R. Lorch, A. J. Lotka, C. E. Love, C. I. Lubin, E. D. McCarthy, W. H. McEwen, Roy MacKay, H. F. MacNeish, H. W. March, R. H. Marquis, W. T. Martin, R. G. Mason, L. C. Mathewson, W. O. Menge, A. D. Michal, E. W. Miller, Norman Miller, E. C. Molina, Max Morris, Richard Morris, D. C. Morrow, E. J. Moulton, J. R. Musselman, A. L. Nelson, M. M. Ness, J. A. Nyswander, F. C. Ogg, Rufus Oldenburger, E. G. Olds, F. W. Owens, H. B. Owens, T. S. Peterson, A. E. Pitcher, H. H. Pixley, L. C. Plant, V. C. Poor, Hillel Poritsky, J. E. Powell, Tibor Rado, G. Y. Rainich, W. C. Randels, J. F. Randolph, S. E. Rasor, W. T. Reid, R. G. D. Richardson, H. L. Rietz, G. de B. Robinson, S. L. Robinson, J. B. Rosenbach, H. A. Ruger, Nathan Schwid, W. A. Shewhart, C. G. Shover, T. M. Simpson, M. E. Sinclair, M. M. Slotnick, Virgil Snyder, G. G. Speeker, V. E. Spencer, C. C. Spooner, G. W. Starcher, J. D. Tamarkin, M. E. Taylor, W. C. Taylor, C. B. Tompkins, C. C. Torrance, P. L. Trump, H. S. Vandiver, J. H. Van Vleck, H E. Vaughan, C. C. Wagner, L. E. Ward, J. F. Wardwell, J. H. Weaver, K. W. Wegner, E. T. Welmers, E. A. Whitman, G. T. Whyburn, R. L. Wilder, S. S. Wilks, K. P. Williams, E. W. Wilson, L. A. Wolf, M. C. Wolf, F. E. Wood, F. L. Wren, Leo Zippin. 
The colloquium lectures, on Fermat's last theorem and related topics in number theory, were delivered by Professor H. S. Vandiver on Tuesday, Thursday, and Friday afternoons. These lectures, for which approximately one hundred persons were registered, will appear in book form.

By invitation of the Committee on Program Professor G. Y. Rainich spoke Wednesday morning on Remarks on product integrals and their applications to geometry, and Professor G. T. Whyburn gave a lecture Friday morning entitled $O n$ the structure of continua.

A joint meeting of the Society and the newly formed Institute of Mathematical Statistics was held on Thursday morning for the completion of the organization of the Institute and for the presentation of papers on mathematical statistics. A constitution was adopted and the following officers were elected: President, Professor H. L. Rietz of the University of Iowa; Vice-President, W. A. Shewhart of the Bell Telephone Laboratories; Secretary-Treasurer, A. T. Craig of the University of Iowa. A resolution was passed that the Institute hold its meetings either in conjunction with the meetings of the American Mathematical Society or with those of the American Statistical Association.

Monday evening an informal reception was held for the visiting mathematicians at the Michigan Women's League, and Thursday afternoon a tea was given by the ladies of the Department of Mathematics of the University of Michigan. At the close of the session on Tuesday afternoon a group picture was taken. This picture will not be published, but a list of the 194 persons present may be obtained from the Secretary.

Wednesday afternoon was devoted to an excursion to Dearborn. Part of the group visited the Ford Factory, and others went to the Greenfield Village and Museum.

A joint dinner of the Mathematical Association of America, the Institute of Mathematical Statistics, and the American Mathematical Society was held Thursday evening in the ballroom of the Michigan League. Professor H. E. Buchanan acted as toastmaster. He called first upon E. H. Kraus, Dean of the College of Literature and Science, who welcomed the mathematicians to the University of Michigan. He then called upon Professor D. R. Curtiss representing the Association. Professor 
H. L. Rietz described the plans of the new Institute of Mathematical Statistics, and Professor J. D. Tamarkin spoke on the unnecessary and unsatisfactory problems of an editor of a scientific journal. The dinner was attended by one hundred eighty-eight persons.

At the meeting on Friday afternoon a motion of thanks was passed to Professor Hildebrandt and the members of his department, to the President and Regents of the University of Michigan, to the management of the Ford Motor Company and the Greenfield Village, and to Professor Vandiver.

The dormitories of the University and the Women's League were open for the mathematicians and their guests.

A meeting of the Council was held at 6:00 P.M. on Tuesday in the Alumnæ Room of the Michigan League. At the business meeting held on Wednesday morning the election of the following persons to membership in the Society was announced by the Secretary:

Professor John Anderson, The Citadel, The Military College of South Carolina;

Professor Leo Avedis Aroian, Colorado State College;

Mr. Edward Thomas Ashman, Darien High School, Darien, Conn.;

Dr. Frances Ellen Baker, Vassar College;

Professor Burton Linton Beegle, Seattle Pacific College, Seattle, Wash.;

Mr. Elmer Elsworth Haskins, Northeastern University;

Professor Irving Kittell, University of Washington;

Miss Madeline Levin, Hunter College;

Professor Roy MacKay, Eastern New Mexico Junior College, Portales, N. Mex.;

Mr. Walter F. Penney, Metropolitan Life Insurance Co., 1 Madison Avenue, New York City;

Mr. Alvin Sugar, 4358 Drexel Blvd., Chicago, Ill.

As nominees of Brown University:

Mr. Nelson Dunford, Brown University;

Mr. Hugh James Hamilton, Brown University;

Mr. John Dillard Hill, Brown University;

Mr. Edward Schaumberg Quade, Brown University.

As nominee of Haverford College:

Mr. Carl B. Allendoerfer, Princeton University.

As nominees of the State University of Iowa:

Mr. Edgar Graham Harrell, State University of Iowa;

Mr. Irvin F. Keeler, State University of Iowa;

Mr. Arthur Ollivier, State University of Iowa; 
[November,

Mr. Merrill Edward Shanks, State University of Iowa;

Mr. Emmet Carson Stopher, State University of Iowa.

As nominees of The Johns Hopkins University:

Dr. Edward Whitney Cannon, The Johns Hopkins University;

Dr. William Henry Erskine, The Johns Hopkins University;

Mr. R. H. Fox, The Johns Hopkins University;

Mr. James Howard Kenna, St. Mary's Seminary, Baltimore, Md.;

Mr. Richard Brandon Kershner, The Johns Hopkins University;

Mr. R. Rawhouser, The Johns Hopkins University.

As nominee of the Department of Mathematics of the University of Kentucky:

Mr. Nathan B. Allison, University of Kentucky.

As nominee of The College of St. Thomas:

Mr. Leonard William Nosker, College of St. Thomas.

As nominee of Williams College:

Professor Elmer Irwin Shepard, Williams College.

As nominee of The University of Wisconsin:

Miss Margarete C. Wolf, University of Wisconsin.

It was announced that the following person had entered the Society under the reciprocity agreement with the Deutsche Mathematiker-Vereinigung:

Dr. Olga Taussky, 39 Eckpergasse, Vienna 18, Austria.

The following thirty-one institutions of learning and mathematical groups were elected to institutional membership in the Society:

Brown University; Bryn Mawr College; University of Buffalo; University of California; University of California at Los Angeles; Case School of Applied Science; University of Cincinnati; Colorado College; Department of Mathematics of the University of Colorado; Cornell University; University of Florida; Johns Hopkins University; Department of Mathematics of the University of Kentucky; University of Michigan; New York University; Oberlin College; Ohio State University; Department of Mathematics of the University of Oklahoma; General Research Council of the State of Oregon; University of Pittsburgh; University of Rochester; Rutgers University; College of St. Thomas; Stanford University; Department of Mathematics of Swarthmore College; Syracuse University; University of Washington; Department of Mathematics of Washington University; Wells College; Western Reserve University; University of Wisconsin.

The following appointments by President Lefschetz were reported: as representative of the Society at the Seventh American Scientific Congress in Mexico City, September 8-17, 
1935 : Professor E. V. Huntington (Professor Huntington was also appointed official delegate of the United States Government); as additional members of the Committee on the SemiCentennial Celebration of the Founding of the American Mathematical Society: Professors Solomon Lefschetz, M. H. Ingraham, J. R. Kline, and T. M. Putnam, all ex officio, Dr. T. C. Fry, and Professor H. S. White. (Professor R. C. Archibald was made Vice-Chairman and Dr. T. C. Fry Executive Secretary.)

Associate Secretary M. H. Ingraham presented a resumé of his year's work in the interest of the finances of the Society. A resolution of appreciation of the work done by Professor Ingraham was unanimously passed by the Council as follows:

Whereas, due to a change in policy of the Rockefeller Foundation which necessitated the withdrawal of their direct financial support to the American Mathematical Society, the efficient continuance of the publication program of the Society was threatened; and

WhEREAS, in order that the necessary income should be forthcoming promptly, it appeared necessary to the Council of the Society that the measures proposed for raising the additional funds made necessary by this contingency be explained in person to a large proportion of the leading universities and of the members; and

Whereas, Professor M. H. Ingraham was willing to undertake for the Society, with the support of the Rockefeller Foundation, this delicate and difficult task at considerable sacrifice to his personal plans; and

WhereAs, by testimony from many sources it has become evident that his efforts have not only achieved their financial purpose, but have at the same time awakened renewed interest in and friendship for the Society among the various universities;

Therefore, BE IT Resolved: that the Council of the Society, mindful of the tactful and efficient manner in which this commission was executed, does hereby tender its profound appreciation to Professor Ingraham, and instruct the Secretary to convey to him a copy of this resolution.

This resolution was adopted by the Society, as was also a resolution of thanks to the Rockefeller Foundation in connection with their support of Professor Ingraham's undertaking. 
The Secretary reported that Vice-President Vannevar Bush of the Massachusetts Institute of Technology had accepted the invitation to give the twelfth Josiah Willard Gibbs Lecture at the Annual Meeting of 1935 in St. Louis.

Professors E. P. Lane and Oystein Ore were appointed the representatives of the Society on the editorial committee of the Duke Mathematical Journal. On recommendation of the Council, the Society approved a change in the by-laws which sets aside four dollars and fifty cents of the dues of each member for a year's subscription to the Bulletin, rather than five dollars as now specified.

The following members presided at various sessions: Professors A. A. Bennett, G. A. Bliss, W. H. Bussey, D. C. Gillespie, E. R. Hedrick, T. H. Hildebrandt, Dunham Jackson, E. P. Lane, H. L. Rietz, Virgil Snyder, and R. L. Wilder. The titles and cross references to abstracts of the papers read follow: papers numbered 1 to 9 were presented Tuesday afternoon; papers numbered 10 to 13 Wednesday morning; papers 14 to 24 Thursday morning; papers 25 to 28 Thursday afternoon; papers 29 to 32 Friday morning; and papers 33 to 35 Friday afternoon. The remainder were read by title at the session on Friday afternoon. Mr. A. G. Swanson was introduced by Professor C. C. Craig, Mrs. G. T. Whyburn by Professor G. T. Whyburn, Mr. H. J. Hamilton by Professor E. R. Hedrick, and Mr. J. W. Wrench, Jr. by Professor H. M. Gehman. Paper number 7 was presented by Dr. E. R. Lorch, number 10 by Professor Virgil Snyder, number 22 by Dr. Leo Zippin, and number 26 by Professor H. E. Buchanan.

1. Symmetric functions of matrices, by Dr. M. C. Wolf. (Abstract No. 41-7-274.)

2. Waring's problem and diophantine equations, by Professor A. J. Kempner. (Abstract No. 41-9-333.)

3. On the fundamental region of an orthogonal representation of a finite group, by Dr. G. de B. Robinson. (Abstract No. 41-7-283.)

4. Fundamental regions in $S_{12}$ for the simple collineation group of order 1092 on seven variables, by Professor M. M. Culver. (Abstract No. 41-9-307.)

5. Solutions of bounded variation of the Volterra-Stieltjes integral equation, by Dr. F. G. Dressel. (Abstract No. 41-9-324.) 
6. Generalizations of the Riemann-Lebesgue theorem. I, by Professor R. P. Agnew. (Abstract No. 41-7-282.)

7. The integral representation of unbounded self-adjoint transformations in Hilbert space, by Professor F. Riesz and Dr. E. R. Lorch. (Abstract No. 41-9-323.)

8. On Volterra-Stieltjes integral equations, by Dr. W. C. Randels. (Abstract No. 41-9-316.)

9. Sufficient conditions by expansion methods for the problem of Lagrange in the calculus of variations, by Dr. W. T. Reid. (Abstract No. 41-11-379.)

10. The Veneroni transformation in $S_{n}$, by Professors Virgil Snyder and Evelyn Carroll-Rusk. (Abstract No. 41-9-327.)

11. The neighborhood of a sextactic point on a plane curve, by Professor E. P. Lane. (Abstract No. 41-7-268.)

12. Notes on Riemannian and non-Riemannian differential geometry in abstract spaces, by Professor A. D. Michal. (Abstract No. 41-9-303.)

13. Variations on Bernstein's theorem, by Professor Dunham Jackson. (Abstract No. 41-9-332.)

14. The sampling theory of systems of variances, covariances, and intraclass covariances, by Dr. S. S. Wilks. (Abstract No. 41-7-288.)

15. Note on a certain bilinear form that occurs in statistics, by Professor A. T. Craig. (Abstract No. 41-9-297.)

16. On the frequency distributions of certain ratios, by Professor H. L. Rietz. (Abstract No. 41-9-321.)

17. Sheppard's corrections for a discrete variate, by Professor C. C. Craig. (Abstract No. 41-9-299.)

18. Factorial moments, by Mr. A. G. Swanson. (Abstract No. 41-11-380.)

19. Relations between two sets of variates, by Professor Harold Hotelling. (Abstract No. 41-9-342.)

20. An integral invariant of $n$-dimensional shells in $(2 n-1)$ space, by Mr. C. B. Tompkins. (Abstract No. 41-9-294.)

21. The strong symmetrical cut-sets of closed euclidean n-space, by Professor R. L. Wilder. (Abstract No. 41-7-267.)

22. Periodic one-parameter groups in three-space, by Dr. Deane Montgomery (National Research Fellow) and Dr. Leo Zippin. (Abstract No. 41-7-280.) 
23. Paratingents in topological spaces, by Dr. C. C. Torrance. (Abstract No. 41-9-328.)

24. Rotations around a set of fixed points, by Mrs. G. T. Whyburn. (Abstract No. 41-11-381.)

25. On the principles of Hamilton and Cartan, by Professor J. W. Campbell. (Abstract No. 41-5-262.)

26. On the characteristic exponents in certain types of problems of mechanics, by Professors H. E. Buchanan and W. L. Duren. (Abstract No. 41-7-281.)

27. Geometrical representation of the growth of entire functions of several complex variables, by Dr. W. T. Martin (National Research Fellow). (Abstract No. 41-9-302.)

28. On generalizations of length and area, by Dr. J. F. Randolph. (Abstract No. 41-9-304.)

29. On the fundamental number of a rational generalized quaternion algebra, by Professor C. G. Latimer. (Abstract No. 41-7-264.)

30. Similarity of matrices in which the elements are real quaternions, by Dr. L. A. Wolf. (Abstract No. 41-9-331.)

31. Characteristic spaces associated with a matrix whose elements belong to a division algebra, by Professor M. H. Ingraham. (Abstract No. 41-9-301.)

32. Anormal systems of numeration, by Professor A. J. Kempner. (Abstract No. 41-9-335.)

33. The simple group of order 25920 (preliminary report), by Dr. J. S. Frame. (Abstract No. 41-9-293.)

34. A classification of certain sequences of polynomials associated with persymmetric determinants, by Miss V. E. Spencer. (Abstract No. 41-9-305.)

35. Some theorems on the maximum sum of ordinals, by Dr. Ben Dushnik. (Abstract No. 41-9-300.)

36. Representation of binary forms by sets of ternary forms, by Mr. D. M. Dribin. (Abstract No. 41-9-325-t.)

37. Abstract continuous groups. I: Linear spaces, by $\mathrm{Mr}$. Garrett Birkhoff. (Abstract No. 41-7-266-t.)

38. On the combination of topologies, by Mr. Garrett Birkhoff. (Abstract No. 41-5-263-t.)

39. Interpolation in non-regularly distributed points, by Dr. J. H. Curtiss. (Abstract No. 41-9-308-t.)

40. Properties of branch-point manifolds associated with linear 
systems of primals, by Professor T. R. Hollcroft. (Abstract No. 41-9-320-t.)

41. The metric characterization of the $n$-dimensional hyperbolic space, by Dr. L. M. Blumenthal (National Research Fellow). (Abstract No. 41-7-272-t.)

42. Spaces of uncountably many dimensions, by Dr. C. W. Vickery. (Abstract No. 41-9-296-t.)

43. Sufficient conditions that a space be an n-dimensional manifold, by Professor D. W. Woodard. (Abstract No. 41-9-311-t.)

44. Simple algebras of degree $p^{e}$ over a centrum of characteristic $p$, by Professor A. A. Albert. (Abstract No. 41-7-285-t.)

45. On the direct sum in circuit theory, by Professor R. S. Burington. (Abstract No. 41-7-289-t.)

46. General recursive functions of natural numbers, by Dr. S. C. Kleene. (Abstract No. 41-7-286-t.)

47. $\lambda$-definability and recursiveness, by Dr. S. C. Kleene. (Abstract No. 41-7-287-t.)

48. Formal definitions in the theory of ordinal numbers, by Professor Alonzo Church and Dr. S. C. Kleene. (Abstract No. 41-9-319-t.)

49. The probability that the mean of a second sample will differ from the mean of a first sample by less than a certain multiple of the standard deviation of the first sample, by Professor G. A. Baker. (Abstract No. 41-7-269-t.)

50. The probability that the standard deviation of a second sample will differ from the standard deviation of a first sample by less than a certain multiple of the standard deviation of the first sample, by Professor G. A. Baker. (Abstract No. 41-7-270-t.)

51. A postulational treatment of the Poisson law, by Professors A. H. Copeland and Francis Regan. (Abstract No. 41-9-326-t.)

52. A new exposition and chart for the Pearson system of frequency curves, by Professor C. C. Craig. (Abstract No. 41-9298-t.)

53. Some arithmetic means connected with Fourier series, by Dr. L. S. Bosanquet. (Abstract No. 41-7-271-t.)

54. Transformations of multiple sequences, by $\mathrm{Mr} . \mathrm{H} . \mathrm{J}$. Hamilton. (Abstract No. 41-7-275-t.)

55. A generalization of a cyclotomic formula, by Dr. H. S. Grant. (Abstract No. 41-7-284-t.)

56. On the Abel-Poisson summability of derived series of the 
conjugate Fourier series, by Professor A. F. Moursund. (Abstract No. 41-7-290-t.)

57. On a theorem of Plessner, by Dr. W. C. Randels. (Abstract No. 41-9-317-t.)

58. Inequalities for the zeros of Legendre polynomials and related functions, by Professor G. Szegö. (Abstract No. 41-9318-t.)

59. A note on a linear operational equation, by Dr. F. G. Dressel. (Abstract No. 41-9-292-t.)

60. Regular convergence and monotone transformations, by Professor G. T. Whyburn. (Abstract No. 41-5-259-t.)

61. Concerning rationality bases for curves, by Professor G. T. Whyburn. (Abstract No. 41-7-291-t.)

62. Sequences of transformations in a general metric space, by Mr. J. W. Wrench, Jr. (Abstract No. 41-9-306-t.)

63. Concerning distance functions and point functions, by Dr. C. W. Vickery. (Abstract No. 41-9-295-t.)

64. On extending a homeomorphism between two subsets of spheres, by Professor H. M. Gehman. (Abstract No. 41-9-329-t.)

65. Algebraic characterizations in complex differential geometry, by Professor T. Y. Thomas. (Abstract No. 41-5-261-t.)

66. Abstract euclidean spaces. III, by Mr. I. E. Highberg, Professor A. D. Michal, and Mr. A. E. Taylor. (Abstract No. 41-9-309-t.)

67. An existence theorem for a second order differential system with two-point boundary conditions in general analysis, by Professor A. D. Michal and Mr. D. H. Hyers. (Abstract No. 41-9-310-t.)

68. Note on line configurations, by Professor W. G. Warnock. (Abstract No. 41-9-337-t.)

69. Some non-involutorial space transformations associated with pencils of nodal cubic surfaces, by Professor H. A. Davis and Dr. Amos Black. (Abstract No. 41-9-312-t.)

70. A series of involutorial Cremona space transformations defined by a pencil of ruled cubic surfaces, by Dr. Amos Black. (Abstract No. 41-9-313-t.)

71. Irreducible non-projective planar graphs (preliminary report), by Mr. I. N. Kagno. (Abstract No. 41-5-260-t.)

72. Differentiable manifolds in euclidean space, by Professor Hassler Whitney. (Abstract No. 41-9-314-t.) 
73. Differential geometry of a certain type of surface in $S_{4}$, by Professor V. G. Grove. (Abstract No. 41-7-273-t.)

74. On the representation of a polynomial in a Galois field as the sum of an odd number of squares, by Professor Leonard Carlitz. (Abstract No. 41-7-277-t.)

75. On sums of squares of polynomials, by Professor Leonard Carlitz. (Abstract No. 41-7-278-t.)

76. On certain higher congruences, by Professor Leonard Carlitz. (Abstract No. 41-7-279-t.)

77. Note on higher congruences, by Professor Leonard Carlitz. (Abstract No. 41-9-336-t.)

78. General relations between Bernouilli, Euler, and allied polynomials, by Professor E. T. Bell. (Abstract No. 41-7-265-t.)

79. On the matric equations $P(A, X)=0$ and $P(X)=A$, by Professor E. T. Browne. (Abstract No. 41-7-276-t.)

80. Remarks on "unsolvability," by Professor A. J. Kempner. (Abstract No. 41-9-334-t.)

81. Binary quadratic discriminants differing by square factors, by Professor Gordon Pall. (Abstract No. 41-9-322-t.)

82. Note on the quadratic subfields of a generalized quaternion algebra, by Professor C. G. Latimer. (Abstract No. 41-9-315-t.)

83. A non-involutorial Cremona transformation belonging to the complex of secants of a twisted cubic, by Professor H. A. Davis and Dr. Amos Black. (Abstract No. 41-9-330-t.)

84. Trigonometric series and power series with repeatedly monotonic coefficients, by Professor L. Fejér. (Abstract No. 41-9-340-t.)

85. Some problems of closest approximation by means of trigonometric sums, by Professor Dunham Jackson. (Abstract No. 41-9-341-t.)

86. Fuchsian groups and ergodic theory, by Professor Eberhard Hopf. (Abstract No. 41-11-378-t.)

R. G. D. RichaRdson, Secretary 